\title{
Measuring the Impact of Arthritis on Worker Productivity: Perspectives, Methodologic Issues, and Contextual Factors
}

\author{
KENNETH TANG, REUBEN ESCORPIZO, DORCAS E. BEATON, CLAIRE BOMBARDIER, DIANE LACAILLE, \\ WEI ZHANG, ASLAM H. ANIS, ANNELIES BOONEN, SUZANNE M.M. VERSTAPPEN, RACHELLE BUCHBINDER, \\ RICHARD H. OSBORNE, BRUNO FAUTREL, MONIQUE A.M. GIGNAC, and PETER S. TUGWELL
}

\begin{abstract}
Leading up to the Outcome Measures in Rheumatology (OMERACT) 10 meeting, the goal of the Worker Productivity Special Interest Group (WP-SIG) was to make progress on 3 key issues that relate to the application and interpretation of worker productivity outcomes in arthritis: (1) to review existing conceptual frameworks to help consolidate our intended target and scope of measurement; (2) to examine the methodologic issues associated with our goal of combining multiple indicators of worker productivity loss (e.g., absenteeism $<->$ presenteeism) into a single comprehensive outcome; and (3) to examine the relevant contextual factors of work and potential implications for the interpretation of scores derived from existing outcome measures. Progress was made on all 3 issues at OMERACT 10. We identified 3 theoretical frameworks that offered unique but converging perspectives on worker productivity loss and/or work disability to provide guidance with classification, selection, and future recommendation of outcomes. Several measurement and analytic approaches to combine absenteeism and presenteeism outcomes were proposed, and the need for further validation of such approaches was also recognized. Finally, participants at the WP-SIG were engaged to brainstorm and provide preliminary endorsements to support key contextual factors of worker productivity through an anonymous "dot voting" exercise. A total of 24 specific factors were identified, with 16 receiving $\geq 1$ vote among members, reflecting highly diverse views on specific factors that were considered most important. Moving forward, further progress on these issues remains a priority to help inform the best application of worker productivity outcomes in arthritis research. (J Rheumatol 2011;38:1776-90; doi:10.3899/jrheum.110405)
\end{abstract}

Key Indexing Terms: ABSENTEEISM PRESENTEEISM

\author{
OSTEOARTHRITIS \\ RHEUMATOID ARTHRITIS
}

OUTCOMES

WORK PRODUCTIVITY
From the Department of Health Policy, Management and Evaluation, University of Toronto; Mobility Program Clinical Research Unit, St. Michael's Hospital; and Institute for Work and Health, Toronto, Canada; ICF Research Branch of WHO Collaborating Centre for the Family of International Classifications in German and the Swiss Paraplegic Research, Nottwill, Switzerland; and Department of Health Sciences and Health Policy, University of Lucerne, Lucerne, Switzerland; Division of Clinical Decision Making and Health Care, Toronto General Research Institute at the University Health Network; Division of Rheumatology, Faculty of Medicine, University of Toronto, Toronto, Ontario; Division of Rheumatology, University of British Columbia; Arthritis Research Centre of Canada; School of Population and Public Health, University of British Columbia; Centre for Health Evaluation and Outcome Sciences, St. Paul's Hospital, Vancouver, Canada; Department of Rheumatology, Maastricht University Medical Center; Caphri Research Institute, Maastricht, The Netherlands; Arthritis Research UK Epidemiology Unit, University of Manchester, Manchester, UK; Monash Department of Clinical Epidemiology, Cabrini Hospital; Public Health Innovation, Population Health Strategic Research Centre, Deakin University, Melbourne, Australia; Department of Rheumatology, APHP Pitié-Salpétriêre Hospital, Pierre et Marie Curie University, Paris, France; Arthritis Community Research and Evaluation Unit; Dalla Lana School of Public Health, University of Toronto, Toronto; and Department of Epidemiology and Community Medicine, University of Ottawa, Ottawa, Ontario, Canada. Supported by the Canadian Arthritis Network (part of the Networks of Centres of Excellence) in partnership with The Arthritis Society and the Research Advisory Council of the Workplace Safety and Insurance Board

\begin{abstract}
of Ontario; by an unrestricted grant from Abbott; and funding provided by OMERACT. K. Tang is supported by a PhD Fellowship from the Canadian Institutes of Health Research, a Canadian Arthritis Network Graduate Award, a Syme Fellowship from the Institute for Work and Health, and an OMERACT Fellow Travel Bursary from the American College of Rheumatology. R. Escorpizo is supported by a grant at Swiss Paraplegic Research and a EULAR travel grant. D.E. Beaton is supported by a Canadian Institutes of Health Research New Investigators Award. C. Bombardier holds a Canada Research Chair in Knowledge Transfer for Musculoskeletal Care. D. Lacaille is supported by an Investigator Award from The Arthritis Society of Canada and is the Nancy and Peter Paul Saunders Scholar. W. Zhang is supported by a Canadian Institutes of Health Research Doctoral Research Award in the Area of Public Health Research and a Canadian Arthritis Network Graduate Award. R.H. Osborne is supported in part by a National Health and Medical Research Council Population Health Career Development Fellowship.

$K$. Tang, MSc(PT), MSc, PhD Student, Department of Health Policy, Management and Evaluation, University of Toronto; $R$. Escorpizo, PT, $M S c, D P T$, Research Scientist, ICF Research Branch of WHO Collaborating Centre for the Family of International Classifications in German and the Swiss Paraplegic Research; D.E. Beaton, PhD, Scientist and Director, Mobility Program Clinical Research Unit, St. Michael's Hospital; Scientist, Institute for Work and Health; Associate Professor, Department of Health Policy, Management and Evaluation, Graduate Department of Rehabilitation Science and Department of Occupational Science and Occupational Therapy, University of Toronto; C. Bombardier, MD, FRCPC, Professor of Medicine, Rheumatology Division Director,
\end{abstract}


Division of Rheumatology and Department of Health Policy, Management and Evaluation, University of Toronto; Division of Clinical Decision Making and Health Care, Toronto General Research Institute, University Health Network; Co-Scientific Director, Canada Arthritis Network; Senior Scientist, Institute for Work and Health and Toronto General University Health Network; Rheumatologist, Mount Sinai Hospital; D. Lacaille, MD, MHSc, FRCPC, Assistant Professor, Division of Rheumatology, University of British Columbia; Research Scientist, Arthritis Research Centre of Canada; W. Zhang, MA, PhD Student, School of Population and Public Health, University of British Columbia; A.H. Anis, PhD, Professor, School of Population and Public Health, University of British Columbia; Director, Centre for Health Evaluation and Outcomes Sciences, Providence Health Care; A. Boonen, MD, PhD, Assistant Professor of Rheumatology, Department of Rheumatology, Maastricht University Medical Center, and Caphri Research Institute; S.M.M. Verstappen, PhD, Research Fellow, Arthritis Research UK Epidemiology Unit, the University of Manchester; R. Buchbinder, MBBS (Hons), PhD, FRACP, Director, Monash Department of Clinical Epidemiology, Cabrini Hospital; Professor, Department of Epidemiology and Preventive Medicine, School of Public Health and Preventive Medicine, Monash University; R.H. Osborne, PhD, Professor and Director, Public Health Innovation, Population Health Strategic Research Centre, Deakin University; B. Fautrel, MD, PhD, Professor of Rheumatology, Pierre et Marie Curie University, Department of Rheumatology, APHP Pitié-Salpétriêre Hospital; M.A.M. Gignac, PhD, Senior Scientist, Division of Health Care and Outcomes Research, Toronto Western Research Institute at the University Health Network; Research Investigator, Arthritis Community Research and Evaluation Unit; Associate Professor, Dalla Lana School of Public Health, University of Toronto; P.S. Tugwell, MD, Professor, Medicine, Epidemiology and Community Medicine, University of Ottawa; Director, Centre for Global Health, Institute of Population Health, University of Ottawa; and Rheumatologist, Ottawa Hospital.

Address correspondence to D.E.Beaton.E-mail: beatond@smh.ca

At the Outcome Measures in Rheumatology Clinical Trials (OMERACT) 9 meeting we provided an update on the 21 available measures that assess the impact of health on work, and the available OMERACT filter evidence in either arthritis or other musculoskeletal disorders ${ }^{1}$. Recent studies and reviews have shown an increasing interest to assess the impact of arthritis on work from different perspectives $1,2,3,4,5$. For example, some measures are designed to assess impacts on worker productivity $6,7,8,9$, by quantifying or monetizing losses in work time or output associated with health-related work absences (absenteeism), as well as reduced performance at work in terms of both quantity and quality (presenteeism). This perspective is considered most relevant in health economics research ${ }^{10,11}$. Other measures are intended to provide a more clinical or disability-oriented perspective of the impact of health on work ${ }^{12,13,14,15}$, for example, by assessing the degree of difficulty associated with the performance of specific work-related tasks ${ }^{13}$. Recent studies have shown only weak-to-moderate associations between productivity- and disability-oriented type instruments $^{2,16}$, thus differences in conceptual foci among available tools remain important to recognize.

The choice of measure(s) to be considered for recommendation is currently being guided by the availability of OMERACT filter evidence ${ }^{17}$, including head-to-head comparisons across tools $2,10,16,18,19,20,21$. At OMERACT 9, we had identified 6 measures $7,13,14,22,23,24$ as the most promising candidates to continue our work forward, and had received endorsement at the OMERACT plenary session for an updated definition of absenteeism that includes an expanded set of indicators ${ }^{1}$. Since that time, we have held 3 meetings (EULAR, 2009; Vancouver, 2009; Paris, 2010) that have served the OMERACT agenda, and as well have initiated a new collaborative group (I-CAN-WORK Alliance) in the area of arthritis and work. Leading up to OMERACT 10, the main objective of the Worker Productivity Special Interest Group (WP-SIG) was to examine issues related to the interpretation of numeric scores on our candidate outcomes, rather than the choice of instruments itself. We were challenged to make progress on 3 issues: (1) to reexamine and consolidate our intended measurement target by reviewing pertinent theoretical frameworks; (2) to examine methodologic issues associated with the goal of capturing both absenteeism and presenteeism with a single comprehensive outcome; and (3) to examine the contextual nature of work and its implications for the interpretation of scores derived from our outcomes. The purpose of this article is to describe our progress along each of these objectives.

\section{GUIDING THEORETICAL FRAMEWORKS}

Measurement must include a solid theoretical framework one that defines the necessary domains to gather a valid picture of the target concept, and posits the theoretical relationships between factors. In recent meetings, we had identified 3 frameworks that were considered most relevant for understanding the scope of our measurement target and the different components of health-related worker productivity loss.

\section{Adaptation of the Model by Brouwer, et al - Transitioning Between Absenteeism and Presenteeism}

Theoretical relationships between work productivity loss and health-related quality of life indicators were proposed in a framework by Brouwer, et $a l^{25}$. We adapted this framework at OMERACT 9 to emphasize an important concept that workers may transition between states of work absenteeism and presenteeism when there is a change in health status $^{1}$ (Figure 1). This helped us recognize that both absenteeism and presenteeism must be concurrently measured to provide a complete view of the impact of arthritis on work, and that they should also ideally be represented within the same measurement continuum. We believe the lowest level of impact should be represented by a complete absence of both absenteeism and presenteeism ( $0 \%$ productivity loss), while the highest level of impact should be represented by a person not working at all (100\% productivity loss). Evidence from recent costing studies has shown both absenteeism and presenteeism to be contributing sources of health-related worker productivity loss ${ }^{11,26}$, providing empirical support for both components to be measured as 


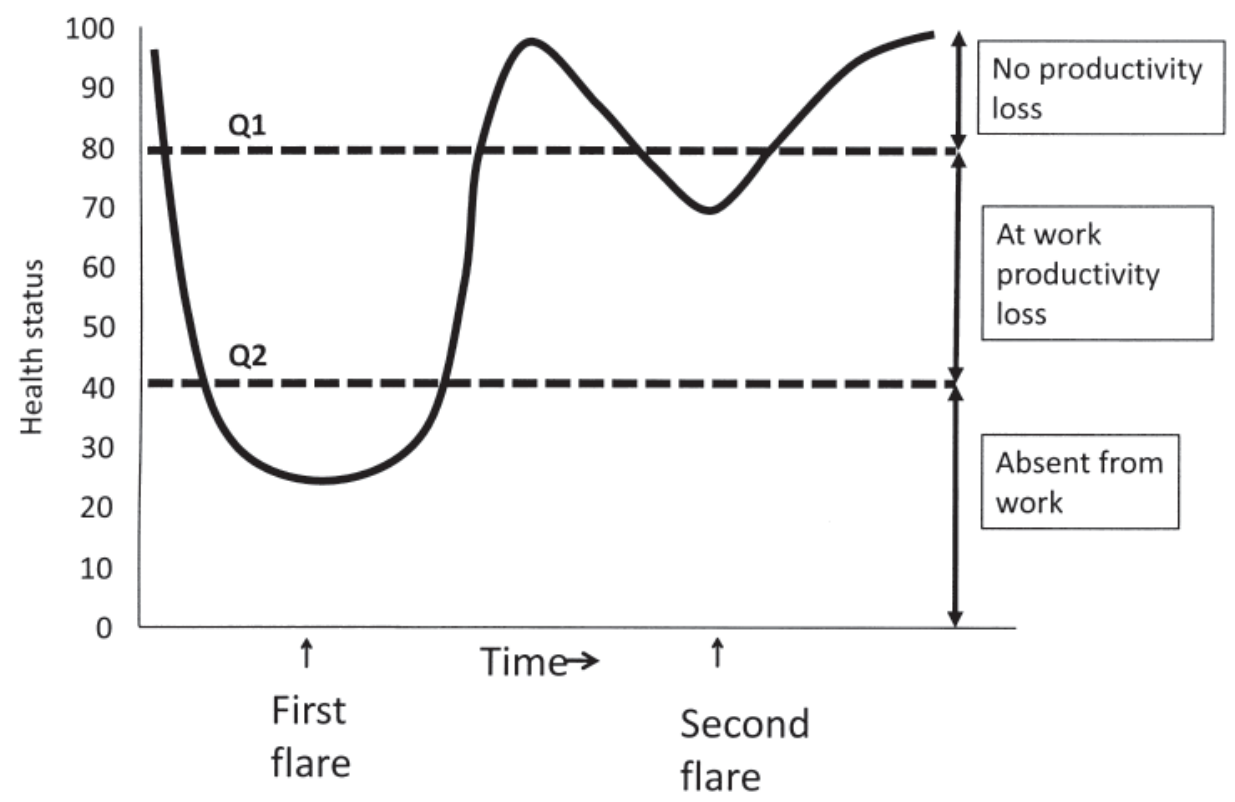

Figure 1. Adaptation of the conceptual model by Brouwer, et $\mathrm{al}^{25}$, which examines the relationship between an individual's health state and level of worker productivity over time. The vertical axis depicts a level of functioning and health, or quality of life ("Health Status"). Two thresholds are defined by the job. The first intersection is Q1, defined as the threshold above which the loss of health does not affect functioning on the job. The second intersection, Q2, defines a threshold below which the individual is unable to work. Between Q1 and Q2 represents the range where there is at-work productivity loss (presenteeism), as the individual is at work but is unable to be as productive as the job demands. Reprinted from Beaton, et al. J Rheumatol 2009;36:2100-9 ${ }^{1}$.

"essential" elements that make up our intended target concept. Thus, the ability to integrate workers' experience of both absenteeism and presenteeism into a single unifying outcome score is imperative for us, as it represents the whole "truth" that we are seeking. Candidate measures should satisfy this requirement.

The contextual nature of worker productivity was also recognized in the original framework by Brouwer, et $a l^{25}$. Two critical thresholds of health status were defined: Q1, above which a person was working without any limitations with a health state exceeding job demands even with mild fluctuations in disease; and Q2, below which persons could not be at work ${ }^{1,25}$. The area between the $2(\mathrm{Q} 1-\mathrm{Q} 2)$ represents at-work productivity loss (presenteeism). This framework allowed for Q1 and Q2 to float, so that a job with a different set of demands relative to a health state might allow someone in a given health state to be at work with no limitations. Other contextual factors and personal characteristics that could influence the positions of the Q1 and Q2 thresholds, however, were not explicitly defined in this framework.

ICF Model. Dissociating the Impact of Arthritis on Work The International Classification of Functioning, Disability and Health (ICF) model $^{27}$ adheres to the biopsychosocial model of disease and recognizes health impacts at 3 inter- related levels: body functions and structures $<->$ activities $\longrightarrow \rightarrow$ participation. Worker productivity loss is generally considered to be most consistent with restrictions at the participation level, reflecting challenges for a person to fulfill a worker role. All our candidate measures are primarily capturing participation restrictions ${ }^{28}$, although several are also capturing limitations at the activities level (e.g., lifting, commuting, etc. $)^{13,14,15}$, or impairments at the level of body functions and structures (e.g., pain, fatigue that relates to work) ${ }^{14,15}$. The role of contextual factors is integral to the ICF framework and provides the link between arthritis (health) and the resultant impact at the 3 levels. In the ICF, contextual factors are organized as "environmental" or "personal" factors, but they can also be differentiated as fixed "scene setters" or modifiable factors that function as either "barriers" or "enablers," according to Badley, et al 29. Environmental factors may include physical, social, structural, or attitudinal factors such as physical environment at work, workplace and health policies, attitudes towards injury, and relationships and roles ${ }^{27,30}$. Personal factors refer to individual characteristics and living background such as age, gender, attitudes and beliefs, ability to cope, socioeconomic status, and also role expectations. According to the ICF, the level of disability experienced by a person is a complex interaction of health, person, and environmental factors and needs to be understood within this broader context ${ }^{27}$. 
Sandqvist and Henriksson Framework - the Importance of Person-Environment "Fit"

A conceptual model developed by Sandqvist and Henriksson $^{31}$ (2004) is another useful perspective on our target concept (Figure 2). This model examines 3 dimensions of work functioning in the context of occupational rehabilitation: individual capacity (physical and psychological attributes), work performance (ability to handle tasks), and work participation (ability to fulfill role of worker) ${ }^{31}$. These dimensions are proposed to have strong parallels with the 3 ICF levels of health impacts. In its core concept, this model posits that the level of work functioning at each of the 3 dimensions is a function of the degree of "fit" between relevant personal and environmental factors, and that the consequences of specific person-environmental mismatches could cross different dimensions ${ }^{31}$. A good fit might mean a worker is still experiencing some pain, fatigue, or disability, but favorable environmental factors like having a flexible work schedule, access to assistive equipment, and social support may enable a person to work to her full capacity. Problems occur in situations where there is a significant person-environment mismatch, which could lead to losses in

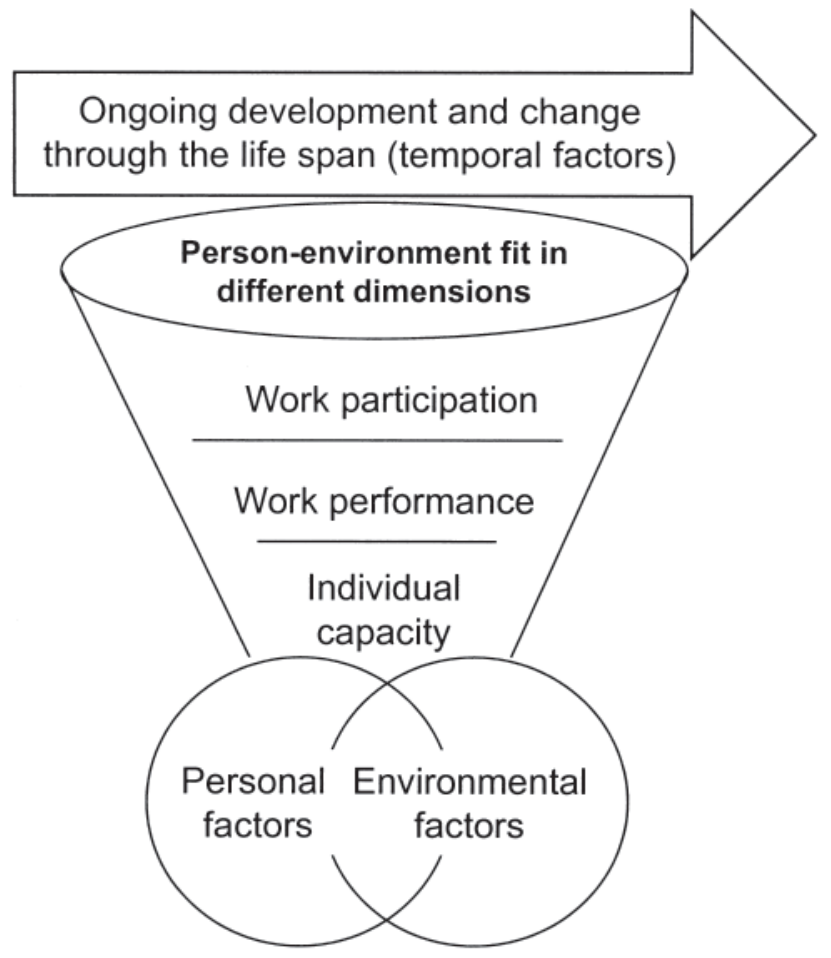

Figure 2. Conceptual framework proposed by Sandqvist and Henriksson ${ }^{31}$. Level of work functioning is represented as a function of the degree of person-environment fit, spanning 3 dimensions: individual capacity, work performance, and work participation. The greater the overlap between the circles representing personal and environmental factors, the better the level of functioning. Interactions between factors are also considered to be dynamic and may vary across time and throughout an individual's life span. Reprinted from Sandqvist and Henriksson. Work 2004;23:147-57; with permission from IOS Press. worker productivity. Recent evidence suggests that person-job mismatches are predictive of adverse future work disability outcomes ${ }^{32,33}$, providing some support for key concepts proposed in this framework.

Collectively, these converging theoretical frameworks have guided our conceptualization of worker productivity, and our understanding of the components that need to be measured in order to comprehensively capture the intended target. Appreciating the way these conceptual frameworks complement each other is important, but differences in scope and focus should also be recognized. For example, the adapted Brouwer, et al model ${ }^{25}$ emphasizes impacts from only the productivity perspective, while the other 2 frameworks were designed to consider impacts at 3 interrelated domains. Also, health/disease state is considered as a "personal" factor in the Sandqvist and Henriksson model ${ }^{31}$, but is a distinct component in the ICF. Nonetheless, moving forward, these frameworks will provide the foundation from which to evaluate the performance of candidate measures, and ultimately, to inform the recommendation of outcomes through the OMERACT process.

Learning points:

Conceptual model by Brouwer, et al ${ }^{1,25}$ :

- Level of worker productivity - a function of health status vs level of job demands

- Workers may transition between absenteeism $<->$ presenteeism states

- Two defined thresholds: below Q1 - able to work but with at-work productivity loss (presenteeism); below Q2: unable to work (absenteeism)

ICF framework ${ }^{27}$ :

- Worker productivity loss - considered an outcome at the participation level

- Interactions between health and contextual factors (environmental and personal factors)

Conceptual Model by Sandqvist and Henriksson ${ }^{31}$ :

- Application of the ICF framework examining domains and factors specific to work

- Importance of person-environment "fit" and its dynamic nature over time

COMBINING ABSENTEEISM AND PRESENTEEISM Meeting Our Vision of "One Target Concept, One Outcome."

Einstein said, "science needs to be as simple as possible but not simpler." Our vision has always been an ambitious one - to be able to comprehensively capture the impact of arthritis on worker productivity with a single outcome; that is, a single value on a metric that ideally can be applied for clinical evaluative or costing purposes. The Brouwer model helped us recognize that absenteeism and presenteeism may 
best be represented as different states along a single continuum. However, the best way to apply measurement tools to operationalize this interrelationship remains unclear. At OMERACT 9, we identified 9 productivity-oriented measures $^{7,8,9,22,24,34,35,36,37}$ that are designed to assess and combine absenteeism and presenteeism, thus the option to use a single outcome to represent the full spectrum of our target concept is available. All such tools similarly emphasize a time-oriented metric to quantify both absenteeism and presenteeism (by estimating or converting scores into equivalent days/hours lost), enabling both components to be summed into a single value. Specific approaches to estimate productivity losses, however, differ widely across instruments, particularly the presenteeism component ${ }^{38}$. In the simplest example, the Health and Labor Questionnaire ${ }^{8}$ simply asks respondents to estimate the number of additional hours they would have worked to compensate for production losses due to illness on working days. Other measures, like the Work and Health Interview ${ }^{7}$, rely on multiple items $(\mathrm{n}=5)$ to quantify reduced work performance, which are translated into a proportion of time impacted. Nonetheless, the general approach to combine absenteeism and presenteeism through a common unit of time-loss or cost appears to have reasonable face validity.

\section{Challenges with Using Presenteeism Measures}

Twelve measures that assess only presenteeism were identified from our recent review ${ }^{1}$. How should we combine these presenteeism scales with absenteeism indicators into a single score? This is a perplexing question that requires continued research and debate. For the purpose of combining scores, it could be argued that multi-item presenteeism scales (that rely on summative scoring) lack compatibility with traditional absenteeism indicators since the latter are often quantified in a more objective manner (e.g., proportion/number of work time missed). Incompatibility of recall periods between absenteeism and presenteeism measures is also a potential issue. The ability to convert presenteeism summative scores into equivalent time-loss/cost values could be one way to combine with absenteeism, although we are aware of this type of conversion for only one of our candidate presenteeism measures. Research by Lerner and colleagues had proposed a regression formula to convert raw Work Limitations Questionnaire-25 score into equivalent percentage productivity loss ${ }^{39}$, although the generalizability of these conversion rates to different types of work and to arthritis populations is unclear. Some considerations for continued research to enable this method of combining absenteeism and presenteeism may be worthwhile, particularly with candidate presenteeism measures that have received some endorsement from past OMERACT meetings.

\section{Methodologic Issues}

The ability to combine absenteeism and presenteeism into a single outcome is also important from a methodologic perspective. Experience has shown that analyzing absenteeism and presenteeism as separate but interrelated outcomes can contribute to a number of practical and computational issues. For example, how should conclusions on the "overall" impact at work be made when differential effects or even conflicting effects are found between absenteeism and presenteeism outcomes? Should we then value changes in one outcome more than the other? When using presenteeism multi-item measures, scoring is problematic when a worker is off-work, since presenteeism becomes an irrelevant concept and can no longer be properly assessed. Should score imputation be performed (e.g., assume maximum score) in these situations? In longitudinal studies, missing-not-at-random data-points ${ }^{40}$ could be generated when workers are transitioning between working and not working over time. This can be difficult to resolve statistically ${ }^{41}$, and contributes to an undesirable burden in certain types of analyses. With absenteeism and presenteeism represented as separate outcomes, another challenge is the interpretability of clinical parameters such as minimal clinical important differences for presenteeism scales. Will these parameters be meaningful at all levels of absenteeism? To put it another way, would a defined level of improvement in presenteeism be similarly meaningful to someone working full-time (low absenteeism) versus someone who is only able to work one day a week due to arthritis (high absenteeism)? Perhaps not. For these reasons, it is important to recognize that using multiple outcomes to represent our intended target concept could complicate data analysis and interpretation, and may represent a methodologic disadvantage.

In spite of our vision of "one concept, one outcome" and the associated methodologic issues, it should be acknowledged that in some instances, keeping absenteeism and presenteeism outcomes separate has proven to be useful and informative. First, there is the obvious advantage of being able to disentangle work impacts into more defined conceptual elements to allow unique changes for each component to be more clearly revealed. Second, separate scales may allow more advanced statistical approaches [e.g., structural equation modeling (SEM)] to assess and better understand the interrelationships between absenteeism and presenteeism and other indicators. In Figure 3, we present a potential application of the 2-part growth modeling approach ${ }^{42}$ in an SEM framework to examine the prognostic factors for both absenteeism and presenteeism over time, while assessing (and controlling for) potential interrelationships between these 2 outcome components, within a single analytical step.

\section{A Potential Strategy to Combine Absenteeism with Presenteeism Multi-item Scales}

Currently, there are no established approaches to combine absenteeism and presenteeism when the latter is assessed with a multi-item scale that is not intended to be directly

Personal non-commercial use only. The Journal of Rheumatology Copyright @ 2011 . All rights reserved. 


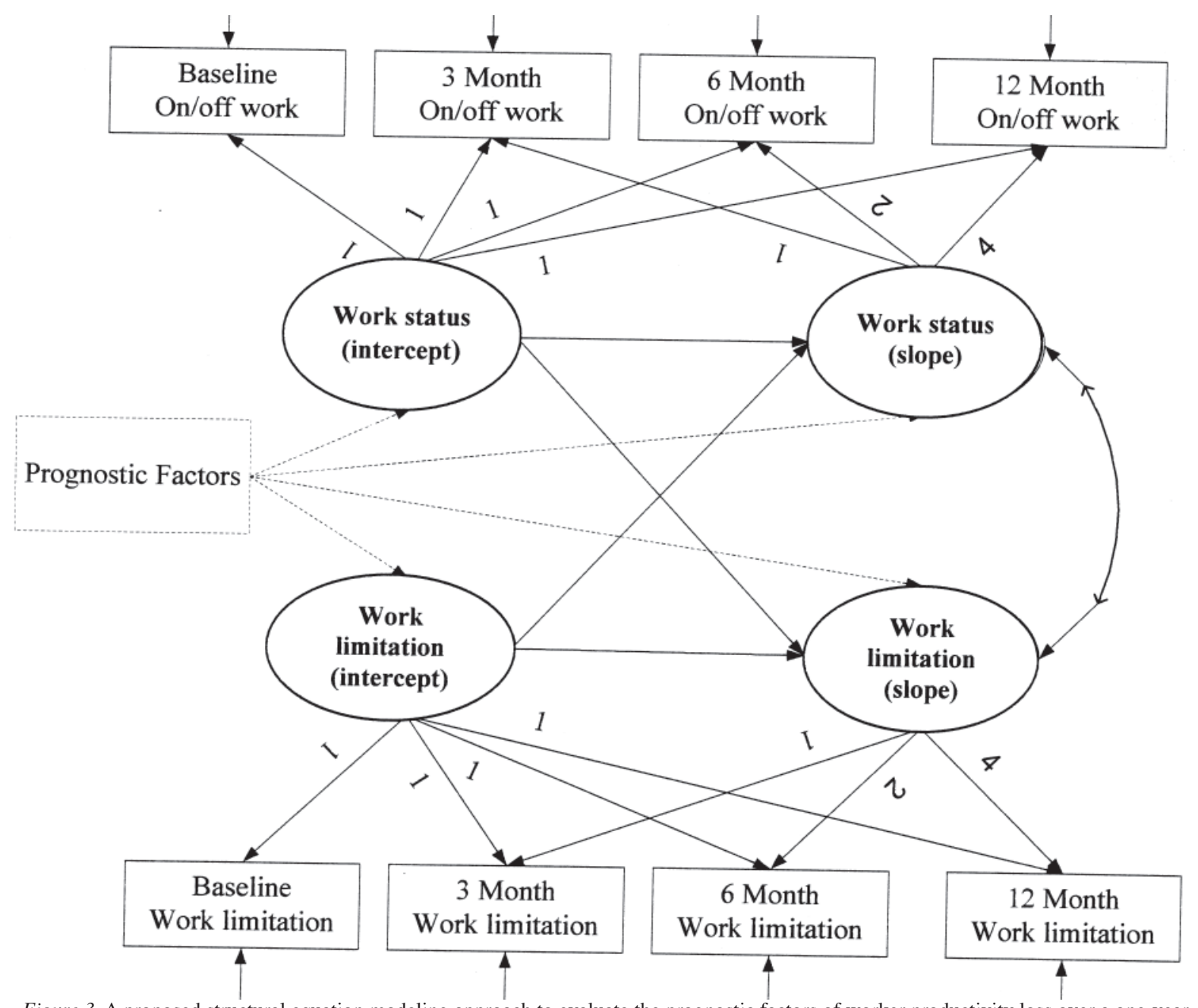

Figure 3. A proposed structural equation modeling approach to evaluate the prognostic factors of worker productivity loss over a one-year period, with both absenteeism (working: on/off) and presenteeism (Work Limitations Questionnaire score) ${ }^{23}$ outcomes represented in a 2-part growth model ${ }^{42}$. This analytic approach specifically permits the interrelationship between absenteeism and presenteeism outcomes (as covariates for each other) to be assessed. Intercepts and slopes for absenteeism assessed at 4 study timepoints are represented by the 2 top circles, while intercepts and slopes for the presenteeism over the 4 timepoints are represented by the 2 bottom circles. Paths (potential relationships) between absenteeism and presenteeism to be evaluated are illustrated by the solid arrows among the 4 circles.

translated into an equivalent time/productivity-loss value. An example of this is the 25-item Endicott Work Productivity Scale (EWPS, range $0-100$, where $100=$ highest presenteeism $)^{43}$. Numerically speaking, a number of arithmetic strategies to combine this with an absenteeism score are possible, but the most sensible or valid approach to do so remains unclear. The simplest approach may be to simply perform a multiplication between the level of absenteeism (percentage proportion of time missed) and the level of presenteeism (summative score), but with both indicators in reverse orientation to avoid numeric operational issues associated with having zero values represent maximum productivity (Figure 4). This would operationalize total worker productivity as a product of the "proportion of expected time at work" (score range 0-1) and the level of "at-work performance" (score range $0-1$, expressed as a proportion of the total presenteeism scale score). For example, a worker working $80 \%$ of his normal work hours at a EWPS reversed score of 90/100 (90\%) would have a total score of $72 \%(0.8$ x $0.9=0.72$; i.e., $28 \%$ productivity loss) to represent the overall impact of arthritis, factoring in both absenteeism and presenteeism elements. A key issue to consider here is whether the constructs representing the 2 components are sufficiently compatible for combination. Further discussion and testing of the validity of such a strategy is anticipated leading up to future meetings.

\section{More Research on Global Indices?}

An approach that has been widely used but somewhat underexplored in the measurement of worker productivity is applying a single global index to simultaneously capture information for both absenteeism and presenteeism. This 


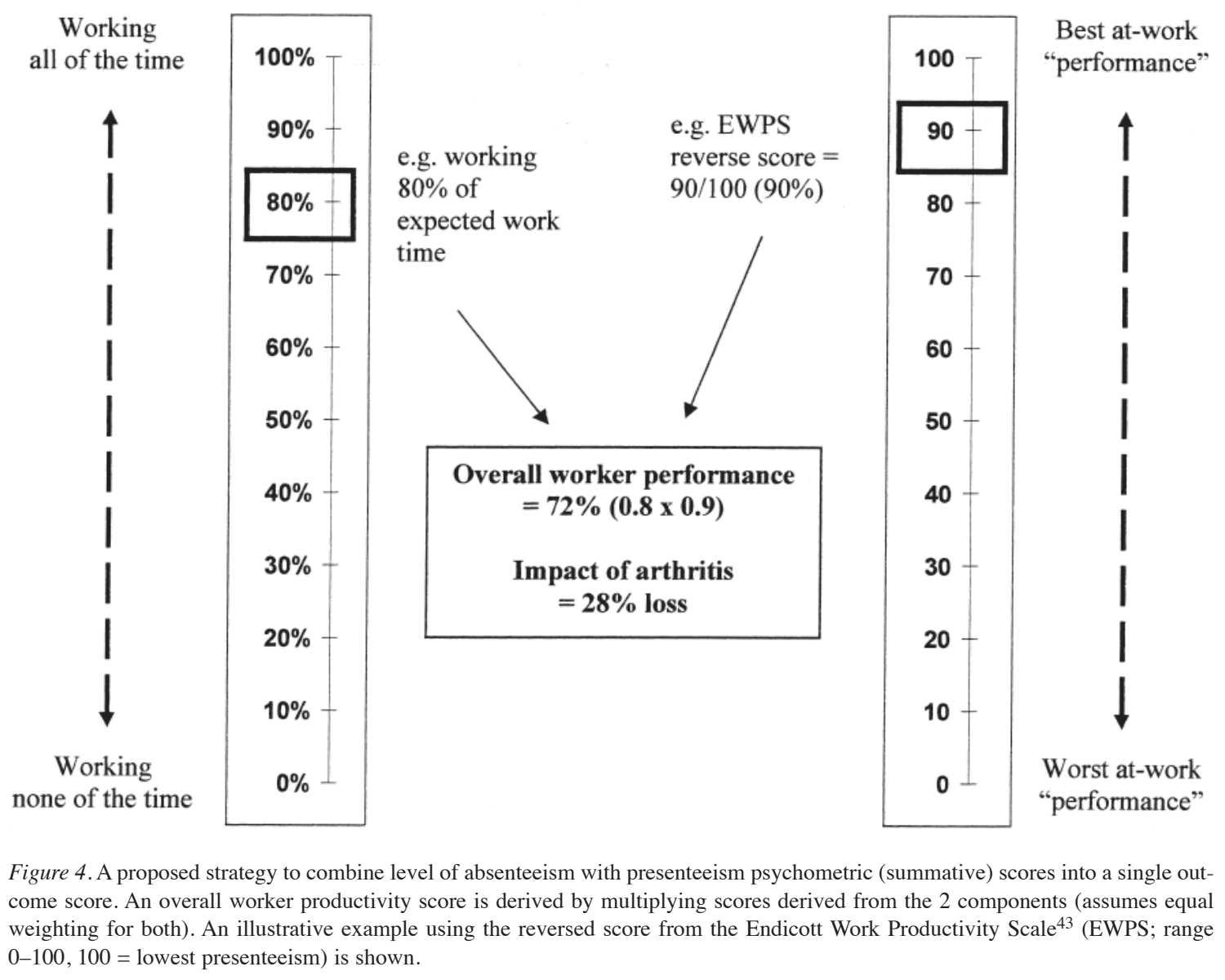

might help mitigate the complexities of having to combine multiple outcomes into a single value. The key to this approach will be to provide the precise scale anchors and instructions so that respondents are primed to concurrently consider experiences related to both absenteeism and presenteeism when using such a tool. In addition to feasibility, a clear advantage is that patients will be allowed to individually determine the relative and perceived impact of their absenteeism and presenteeism experiences, from which to provide a single overall score, as opposed to having this decided $a$ priori by a predetermined scoring algorithm (e.g. addition/multiplication of absenteeism and presenteeism scores, which assumes equal weighting). Certainly, multi-item psychometric scales can provide a detailed view of workers' experiences, but the performance of these scales could also suffer if specific items are not relevant to the individual worker, especially when the outcome concept is highly contextual. While there are a few global indices available for assessing presenteeism ${ }^{22,24,36}$, the potential of using global indices to concurrently capture both absenteeism and presenteeism may deserve further research.
From an economics perspective, the challenge to represent absenteeism and presenteeism with a single outcome has been met by converting both components into a metric appropriate for summing (e.g., equivalent time loss, dollar cost). Challenges remain, however, for presenteeism multi-item scales that are not compatible with such conversions, many of which are of high interest for use, especially for clinicians. We have described a number of potential means to accomplish this that could be considered for further research. These approaches include performing a simple arithmetic computation with an appropriate absenteeism score, adopting a global index, or combining outcomes at the analysis stage using more complex 2-part statistical modeling.

\section{CONTEXTUAL NATURE OF WORK}

Contextual factors play an important role in shaping the nature and extent of arthritis-related impacts ${ }^{44,45,46}$, and it is important to be mindful of this when interpreting changes in worker productivity outcomes. In the pre-OMERACT 9 survey, respondents supported the importance of context in 
assessing work impacts, despite some unfamiliarity with outcomes related to work. Specifically, $62 \%$ of respondents believed that persons with arthritis found ways to work around their disease to allow them to function better at work, $54 \%$ believed work accommodations could help persons with arthritis stay at work, and 52\% agreed that a worker's productivity could not be measured without some understanding of the contextual factors. Recent studies have shown that workplace culture and support, level of job demands, availability of job modifications or accommodations, and co-worker support are important factors for allowing individuals with arthritis to successfully remain at work $^{29,47,48,49,50}$. Adaptations made by the individual worker in order to stay at work are also important ${ }^{13,47,51,52,53}$. Potential societal-level factors, or "macroeconomic conditions" 54 , are also important to recognize. For example, labor market climate ${ }^{55}$, public health policies, and social regulations $^{56}$ (e.g., sick leave and work disability policies, availability of funding for medications and other health benefits) could indirectly impact whether a person with arthritis is able to find suitable employment and be productive at work. Assessments of productivity losses at the "workplace" level may also consider additional factors such as the ability of the company to compensate for absent workers with replacement workers. At OMERACT 10, our main objective was to examine what participants felt were the most relevant contextual factors to consider when using work productivity outcomes, to build on the general opinion from previous survey results.

\section{Contextual Factors of Worker Productivity Identified}

At the WP-SIG, we presented a brief case scenario to engage participants to brainstorm factors that might help a person with arthritis to "make return to work successful, productive, and sustainable." After writing each identified factor on separate cards, we then performed a "dot voting" exercise, where participants were able to anonymously vote for specific factors that they felt were most important to consider (12 votes allowed per participant, multiple votes on same factor permitted). Table 1 summarizes the 24 contextual factors (in their original description) identified during this exercise and the number of votes received from participants. Sixteen of the 24 factors received at least 1 vote, and the 2 top factors were "support at home" and "flexibility of work scheduling" although each received only a modest proportion (13\%) of all votes. This indicates strong diversity of viewpoints in terms of which specific factors were considered most important.

Post-OMERACT 10, these contextual factors were compiled with additional personal and environmental factors that have been discussed conceptually in the literature $6,28,31,44,57$, or have had supporting evidence in arthritis (Table 2). This full list of 70 factors was organized into a proposed 2-tiered classification: (1) as either a personal or environmental factor, and then (2) into one of 15 broad domains: health, demographic attributes, economic need, personal appraisal, related skills/abilities, work-life balance, accessibility, economic climate/labor regulations, nature of work, workplace support, non-workplace support, organizational policies and practices, physical environment, work accommodations, and others. Of further interest was how well these factors could be mapped onto the associated categories of the ICF classification. Based on agreement between 3 coders (KT, RE, AB), we found $35(50 \%)$ of our identified factors had compatibility with existing ICF categories, including a few that were coded outside the sections on contextual factors. This suggests that while all factors are broadly considered in the ICF framework, not all factors demonstrate a precise fit with its classification structure (either too specific or too broad). Also, personal factors remain unspecified in the ICF, and therefore cannot be coded at present.

The current examination of the relevant contextual factors allowed us to elaborate on the conceptual model by Sandqvist and Henriksson ${ }^{31}$. Figure 5 illustrates the range of specific factors that may contribute to the person-environment intersection. Degree of relevance of individual factors (represented by thickness of arrows) is expected to vary between individuals, and may also evolve over time within the individual if there are changes to one's circumstances (e.g., health, work, life events). It is also important to consider that factors may interact not only across but also within the personal and environmental divisions (represented by semicircular arrows linking the factors). For example, the importance of receiving job accommodations may be diminished if a worker has a job with highly flexible work schedule and receives strong support from co-workers. Social support from family/friends may have added importance for a self-employed worker than someone working within a supportive team environment in a larger organization. On the personal side, if economic need is modest for an individual, considerations of job satisfaction and achieving work-life balance may come to the forefront.

\section{Implications for Interpreting Work Productivity Outcomes}

Since level of worker productivity could be viewed as a function of the level of person-environment fit, some care is needed when comparing outcome scores between as well as within the individual. Will the level of worker productivity have the same meaning if the job has changed for the same individual over time? How can we compare between people with different levels of job demand? When there is a change in productivity, how can we know if it is attributable to a change in the worker's health or a change in the level of job demands placed on the individual (by job accommodations, changing jobs, etc.), or both? How could we differentiate a brief episodic versus a more sustained change with these

Personal non-commercial use only. The Journal of Rheumatology Copyright @) 2011. All rights reserved. 
Table 1. Contextual factors identified at the OMERACT 10 Worker Productivity Special Interest Group and number of votes received for each factor during a "dot voting" exercise (12 votes available per participant, multiple votes on same factor permitted).

\begin{tabular}{|c|c|}
\hline Factor Identified & $\begin{array}{c}\text { No. Votes } \\
\text { Received (\%) }\end{array}$ \\
\hline Support at home & $26(13)$ \\
\hline Flexibility of work schedule (to accommodate intermittent flare) & $25(13)$ \\
\hline Employer attitudes towards work accommodations & $22(11)$ \\
\hline Societal incentive to remain employed (e.g., insurance, social security) & $21(11)$ \\
\hline Co-worker attitudes & $19(10)$ \\
\hline Personal incentives to remain employed (e.g., job satisfaction) & $17(9)$ \\
\hline Expectations at work & $12(6)$ \\
\hline Job autonomy & $11(6)$ \\
\hline Availability of medications to manage symptoms & $9(5)$ \\
\hline Nature of work (e.g., part time vs full time) & $9(5)$ \\
\hline Loss of confidence in ability to work, or to go back to work & $7(4)$ \\
\hline Self-employment & $7(4)$ \\
\hline Ability to cope & $6(3)$ \\
\hline Work-life balance (e.g., sacrificing social life) & $5(3)$ \\
\hline Personal incentive (e.g., securing benefits) & $3(2)$ \\
\hline Barriers to mobility (e.g., availability to transportation to/from work) & $1(1)$ \\
\hline Setting, country & 0 \\
\hline Ability to rest & 0 \\
\hline Task support from co-workers & 0 \\
\hline Social support from co-workers and employer & 0 \\
\hline Job accommodations - scheduling, planning of activities, flexibility, ability to prioritize & 0 \\
\hline Seasons (summer vs winter) & 0 \\
\hline Ability to work extra hours to catch up & 0 \\
\hline Work ethic & 0 \\
\hline
\end{tabular}

outcomes? With these issues in mind, it is important not to simply presume that an increase in the level of worker productivity automatically represents an "improvement," or that a decrease in score is synonymous with "deterioration," without some understanding of any concurrent changes to contextual factors. When designing a clinical trial, it may be prudent to measure key contextual factors when using worker productivity outcomes, recognizing the potential for these factors to contribute to confounding bias. For example, data could be collected on whether job accommodations were received by workers, and whether this factor differed between comparison groups over time in a randomized controlled trial. We may also collect data on whether patients had changed jobs over time, and whether this influenced the level of job demands placed on the individual worker. For multicenter trials, we may also examine whether patients from different geographical regions are evenly distributed after randomization such that societal-level contextual factors (that could dictate the availability of sick leave or suitable jobs) would not have biased comparisons across regions. Moving forward, we assert that it will be important to collect data on key contextual factors in future studies to help facilitate a more accurate interpretation of changes in worker productivity. One of our objectives over the next 2 years will be to determine which contextual factors should be considered "essential" to assess in conjunction with worker productivity outcomes, and whether score adjustment strategies based on such factors are appropriate.

\section{LOOKING FORWARD TO OMERACT 11}

The goal of establishing valid outcomes to quantify the impact of arthritis on work has provided us with many challenges from a measurement perspective. The intrinsic broadness of our target concept, the different measurement perspectives and intended applications, the complex interrelationships between components that collectively make up our measurement target (e.g., absenteeism $<->$ presenteeism), and the highly contextual nature of work were among the key issues examined leading up to OMERACT 10. Importantly, these challenges also have given rise to additional questions to be addressed. In our outcome selection process, should we continue to consider measures that represent different perspectives (e.g., productivity loss vs disability)? Do candidate measures need to be able to provide outcome scores that are compatible for different research purposes (e.g., clinical vs costing studies)? Should the continued consideration of presenteeism-only measures in the OMERACT process be contingent on their ability to be combined with absenteeism indicators to provide a single outcome score in a sensible manner? We will continue to focus our efforts towards resolving the issues and questions raised in this article, to help set the stage for the recommen- 
Table 2. Contextual (environmental or personal) factors of worker productivity loss or work disability that have supporting evidence in arthritis, have been discussed conceptually in the literature, or were identified at the OMERACT 10 Work Productivity Special Interest Group. Factors are mapped onto the International Classification of Functioning, Disability and Health (ICF) coding system to access degree of compatibility in terms of classification. For the purpose of brevity, titles of the ICF categories were abbreviated (refer to the ICF handbook for full titles ${ }^{27}$ ).

\begin{tabular}{lcccc}
\hline $\begin{array}{l}\text { Category } \\
\text { (no. factors) }\end{array}$ & Factor & Evidence in Arthritis & $\begin{array}{c}\text { Discussed Conceptually } \\
\text { in Literature or at } \\
\text { OMERACT 10* }\end{array}$ & Fit with \\
ICF? $?^{\dagger \dagger}$ & ICF Code(s)
\end{tabular}

Environmental factors

Accessibility (2)

Barriers to mobility

(difficulty commuting)

Design of work environment

Economic climate/ labor regulations (2)

Employment and career opportunities

Labor and social regulations

Nature of work (9)

Demands (physical)
Demands (work hours)
Demands (workload)
Flexibility
Job autonomy
Job sector/type
Pacing of work
Self-employed

Work status (full vs part time)

Organizational policies $\& \operatorname{practices}^{\dagger}(4)$

Availability of

replacement workers

Compensation of lost productivity for work absences

External time demands

(to complete work)

Team dynamic

Physical environment (3) Sound

Temperature

Weather

Work accommodations Adaptive devices and (4) equipment Flexibility (work schedule) Job accommodations (reduced hours, modified duties) Workstation modification

Workplace support (4)

Co-worker attitude

Employer attitude

Social (co-workers, employer)

$46,47,48,53,58,59$

Task support (co-workers)

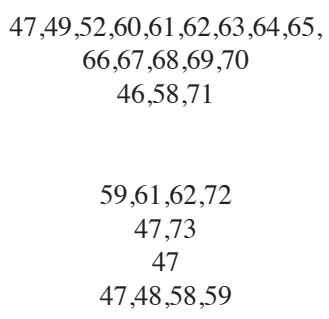

57

6,31

44

31,44

$28 *$

$31 *$

31

6*

6,44

$*$

$*$

6

6*

6

6

28

28,57

*

$28,44,57$

48,52

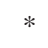

$*$

$*$

$31 *$

$31 *$

$28 *$

6*
$\mathrm{CM}$

CM

$\mathrm{CO}$

$\mathrm{CO}$

$\mathrm{CU}$

CU

$\mathrm{CU}$

$\mathrm{CU}$

$\mathrm{CU}$

$\mathrm{CU}$

$\mathrm{CU}$

$\mathrm{CO}$

$\mathrm{CU}$

$\mathrm{CM}$

CU

$\mathrm{CU}$

CM

$\mathrm{CO}$

$\mathrm{CO}$

$\mathrm{CO}$

$\mathrm{CO}$

CU

$\mathrm{CU}$

$\mathrm{CO}$

$\mathrm{CO}$

$\mathrm{CO}$

$\mathrm{CO}$

$\mathrm{CO}$
Products and technology (e120... for mobility and transportation, e150... of building for public use, e155... of buildings for private use)

Products and technology (e135... for employment) Services, systems and policies (e590 Labor and employment, e5902

Labor and employment policies) Services, systems and policies (e590 Labor and employment, e5902 Labor and employment policies)

ND

$$
\begin{aligned}
& \text { ND } \\
& \text { ND } \\
& \text { ND } \\
& \text { ND } \\
& \text { ND } \\
& \text { ND }
\end{aligned}
$$

Major life areas (d850 Remunerative employment) ND

Services, systems and policies (e590 Labor and employment) ND

ND

Support and relationships (e325... peers, colleagues...) Natural environment (e250 Sound)

Natural environment (e225

Climate, e260 Air quality)

Natural environment (e225 climate)

Products and technology

(e1351... for employment) ND

ND

Products and technology (e1351... for employment) Attitudes (e425...of peers, colleagues...)

Attitudes (e430...of people in positions of authority) Support and relationships (e325...peers, colleagues...) Support and relationships (e325... peers, colleagues...) 
Table 2. Continued.

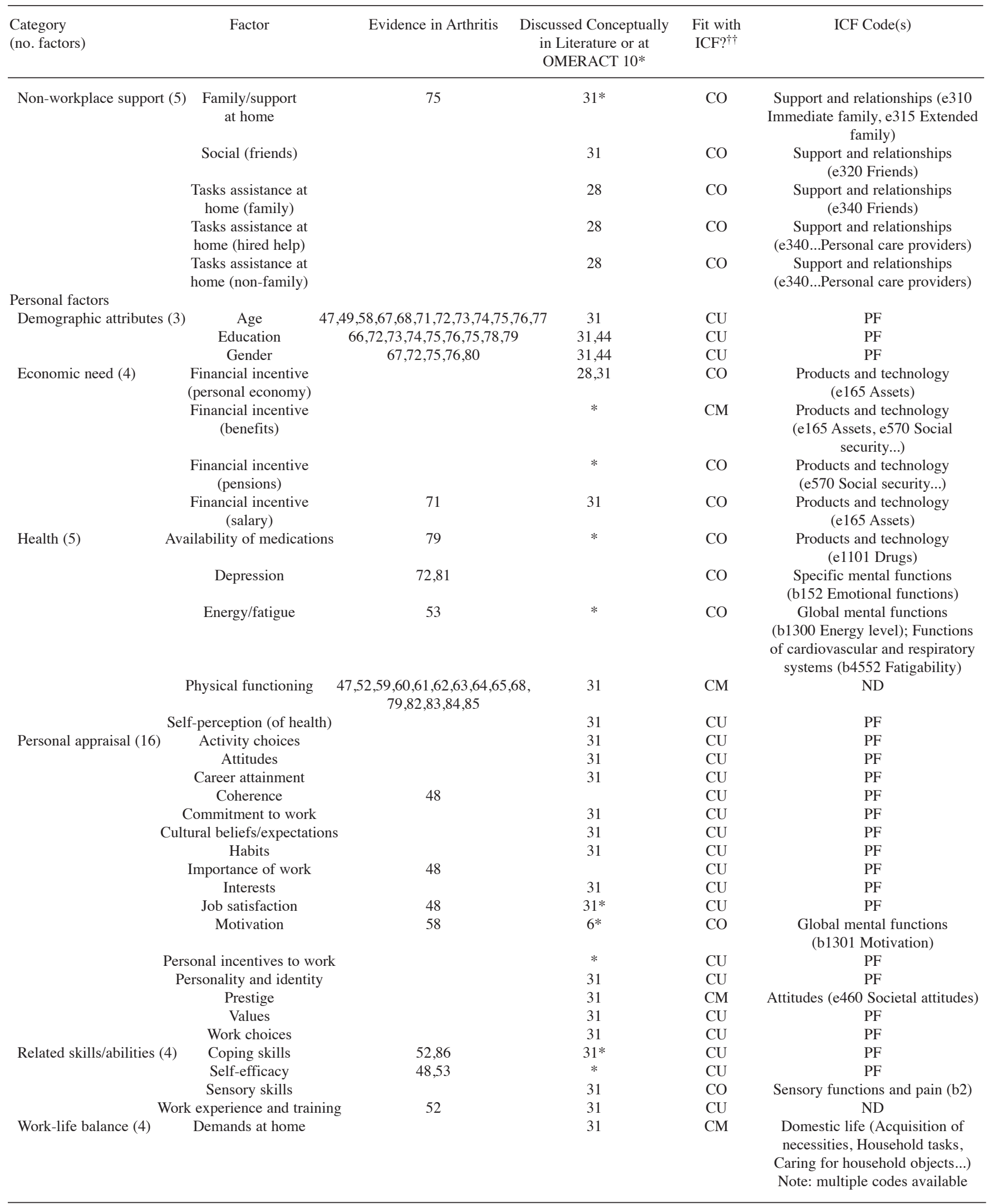




\begin{tabular}{|c|c|c|c|c|c|}
\hline $\begin{array}{l}\text { Category } \\
\text { (no. factors) }\end{array}$ & Factor & Evidence in Arthritis & $\begin{array}{l}\text { Discussed Conceptually } \\
\text { in Literature or at } \\
\text { OMERACT } 10^{*}\end{array}$ & $\begin{array}{l}\text { Fit with } \\
\text { ICF? }{ }^{\dagger \dagger}\end{array}$ & ICF Code(s) \\
\hline Other (1) & Disclosure & $48,52,53,87$ & & $\mathrm{CU}$ & ND \\
\hline
\end{tabular}

${ }^{\#}$ Health factors are considered as personal factors in the conceptual model by Sandqvist and Henriksson ${ }^{31}$, but not necessarily in the ICF ${ }^{27}$. ${ }^{\dagger}$ Some factors associated with organization policies and practices may affect worker productivity primarily at the "workplace" level, rather than at the "individual" level. $\dagger \dagger$ Fit with ICF: consistent (CO), complex (CM), or code unavailable (CU). ND: not defined in the ICF (factor is either too specific or too broad); PF: personal factor (ICF classification codes unavailable).

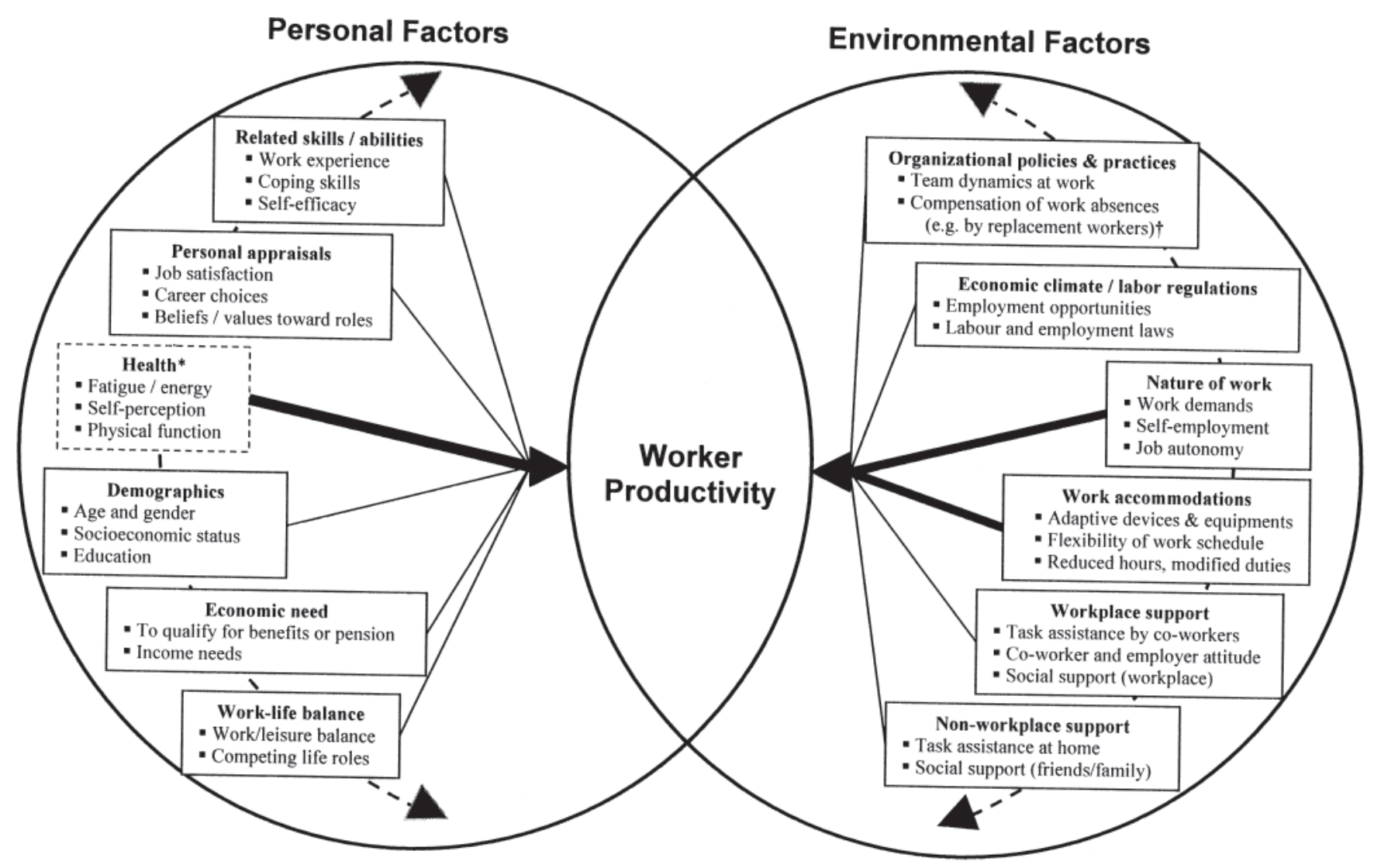

Figure 5. Conceptual representation of the interaction between contextual factors that contribute to the person-environment "fit," to elaborate on the framework on work functioning proposed by Sandqvist and Henriksson ${ }^{31}$. We have depicted level of worker productivity as our measurement target of interest (represented as the area of overlap between the 2 circles). Specific factors and degree of relevance (indicated by thickness of arrows) to the overall construct is expected to vary between individuals, and may also evolve over time within the individual if there are changes in circumstances (e.g., health, work, life events). Factors are also believed to interact with each other within the personal and environmental divisions (semicircular arrows behind the factors). *Some health-related factors may not be represented as "personal" factors in the ICF framework. "Some factors associated with organization policies and practices may affect work productivity primarily at the "workplace" level, rather than at the "individual" level. From Sandqvist and Henriksson. Work 2004;23:147-57. Adapted with permission. 
dation of candidate worker productivity measures at future OMERACT meetings.

\section{Summary of Progress at OMERACT 10}

1. Identified 3 complementary theoretical frameworks to guide our conceptualization of worker productivity: basis for continued evaluation of candidate measures.

2. Proposed a number of potential methodologic approaches to combine absenteeism with presenteeism multi-item measures.

3. Brainstormed and reviewed contextual factors of work productivity, and expanded on the person-environment interaction proposed in the Sandqvist and Henriksson framework $^{31}$.

\section{Future Objectives}

1. To reach consensus on specific domain(s) to be measured in order to capture the full scope of worker productivity.

2. Perform further research to examine the merit (strengths and limitations) of different approaches to combine absenteeism and presenteeism indicators.

3. Define essential contextual factors to be assessed when applying worker productivity outcomes in clinical trials or longitudinal observational studies.

\section{ACKNOWLEDGMENT}

The authors acknowledge all participants of the OMERACT 10 Worker Productivity Special Interest Group for their contributions. We also thank other members of the I-CAN-WORK Alliance for contributions to this work and encouragements to explore contextual factors in this field: Mieke Hazes, Axel Finckh, Catherine Hoffstetter, Marc Koopmanschap, Nick Bansback, Claire McGrath, and Annemarie Braakman-Jansen. We also acknowledge Depeng Jiang for providing consultations on statistical approaches to model absenteeism and presenteeism outcomes.

\section{REFERENCES}

1. Beaton D, Bombardier C, Escorpizo R, Zhang W, Lacaille D, Boonen A, et al. Measuring worker productivity: frameworks and measures. J Rheumatol 2009;36:2100-9.

2. Beaton DE, Tang K, Gignac MA, Lacaille D, Badley EM, Anis AH, et al. Reliability, validity, and responsiveness of five at-work productivity measures in patients with rheumatoid arthritis or osteoarthritis. Arthritis Care Res 2010;62:28-37.

3. Escorpizo R, Bombardier C, Boonen A, Hazes JM, Lacaille D, Strand V, et al. Worker productivity outcome measures in arthritis. J Rheumatol 2007;34:1372-80.

4. Prasad M, Wahlqvist P, Shikiar R, Shih YC. A review of self-report instruments measuring health-related work productivity: a patient-reported outcomes perspective. Pharmacoeconomics 2004;22:225-44.

5. Lofland JH, Pizzi L, Frick KD. A review of health-related workplace productivity loss instruments. Pharmacoeconomics 2004;22:165-84.

6. Koopmanschap MA. PRODISQ: a modular questionnaire on productivity and disease for economic evaluation studies. Expert Rev Pharmacoeconomics Outcomes Res 2005;5:23-8.

7. Stewart WF, Ricci JA, Leotta C, Chee E. Validation of the work and health interview. Pharmacoeconomics 2004;22:1127-40.

8. van Roijen L, Essink-Bot ML, Koopmanschap MA, Bonsel G, Rutten FF. Labor and health status in economic evaluation of health care. The Health and Labor Questionnaire. Int J Technol Assess Health Care 1996;12:405-15.

9. Kumar RN, Hass SL, Li JZ, Nickens DJ, Daenzer CL, Wathen LK. Validation of the Health-Related Productivity Questionnaire Diary (HRPQ-D) on a sample of patients with infectious mononucleosis: results from a phase 1 multicenter clinical trial. J Occup Environ Med 2003;45:899-907.

10. Brouwer WB, Koopmanschap MA, Rutten FF. Productivity losses without absence: measurement validation and empirical evidence. Health Policy 1999;48:13-27.

11. Brouwer WB, van Exel NJ, Koopmanschap MA, Rutten FF. Productivity costs before and after absence from work: as important as common? Health Policy 2002;61:173-87.

12. Koopman C, Pelletier KR, Murray JF, Sharda CE, Berger ML, Turpin RS, et al. Stanford Presenteeism Scale: health status and employee productivity. J Occup Environ Med 2002;44:14-20.

13. Gignac MA, Badley EM, Lacaille D, Cott CC, Adam P, Anis AH. Managing arthritis and employment: making arthritis-related work changes as a means of adaptation. Arthritis Rheum 2004;51:909-16.

14. Gilworth G, Chamberlain MA, Harvey A, Woodhouse A, Smith J, Smyth MG, et al. Development of a work instability scale for rheumatoid arthritis. Arthritis Rheum 2003;49:349-54.

15. Tang K, Beaton D, Lacaille D, Gignac MA, Zhang W, Anis AH, et al. The Work Instability Scale for Rheumatoid Arthritis (RA-WIS) - Does it work in osteoarthritis? Qual Life Res 2010;19:1057-68.

16. Tang K, Pitts S, Solway S, Beaton D. Comparison of the psychometric properties of four at-work disability measures in workers with shoulder or elbow disorders. J Occup Rehabil 2009;19:142-54.

17. Boers M, Brooks P, Strand CV, Tugwell P. The OMERACT filter for Outcome Measures in Rheumatology. J Rheumatol 1998;25:198-9.

18. Meerding WJ, W IJzelenberg, Koopmanschap MA, Severens JL, Burdorf A. Health problems lead to considerable productivity loss at work among workers with high physical load jobs. J Clin Epidemiol 2005;58:517-23.

19. Ozminkowski RJ, Goetzel RZ, Chang S, Long S. The application of two health and productivity instruments at a large employer. J Occup Environ Med 2004;46:635-48.

20. Turpin RS, Ozminkowski RJ, Sharda CE, Collins JJ, Berger ML, Billotti GM, et al. Reliability and validity of the Stanford Presenteeism Scale. J Occup Environ Med 2004;46:1123-33.

21. Lavigne JE, Phelps CE, Mushlin A, Lednar WM. Reductions in individual work productivity associated with type 2 diabetes mellitus. Pharmacoeconomics 2003;21:1123-34

22. Kessler RC, Barber C, Beck A, Berglund P, Cleary PD, McKenas $D$, et al. The World Health Organization Health and Work Performance Questionnaire (HPQ). J Occup Environ Med 2003;45:156-74.

23. Lerner D, Amick BC 3rd, Rogers WH, Malspeis S, Bungay K, Cynn D. The Work Limitations Questionnaire. Med Care 2001;39:72-85.

24. Osterhaus JT, Purcaru O, Richard L. Discriminant validity, responsiveness and reliability of the rheumatoid arthritis-specific Work Productivity Survey (WPS-RA). Arthritis Res Ther 2009;11:R73.

25. Brouwer WB, Meerding WJ, Lamers LM, Severens JL. The relationship between productivity and health-related QOL: an exploration. Pharmacoeconomics 2005;23:209-18.

26. Li X, Gignac MA, Anis AH. The indirect costs of arthritis resulting from unemployment, reduced performance, and occupational changes while at work. Med Care 2006;44:304-10.

27. World Health Organization. International Classification of Functioning, Disability, and Health (ICF). Geneva: World Health Organization; 2001. 
28. Escorpizo R, Cieza A, Beaton D, Boonen A. Content comparison of worker productivity questionnaires in arthritis and musculoskeletal conditions using the International Classification of Functioning, Disability, and Health framework. J Occup Rehabil 2009;19:382-97.

29. Badley EM. Enhancing the conceptual clarity of the activity and participation components of the International Classification of Functioning, Disability, and Health. Soc Sci Med 2008;66:2335-45.

30. Jette AM. Toward a common language for function, disability, and health. Phys Ther 2006;86:726-34.

31. Sandqvist JL, Henriksson CM. Work functioning: a conceptual framework. Work 2004;23:147-57.

32. Tang K, Beaton DE, Gignac MAM, Lacaille D, Zhang W, Bombardier C, et al. The Work Instability Scale for Rheumatoid Arthritis (RA-WIS) predicts arthritis-related work transitions in patients with osteoarthritis or rheumatoid arthritis within 12 months. Arthritis Care Res 2010;62:1578-87.

33. Puolakka K, Kautiainen H, Mottonen T, Hannonen P, Korpela M, Hakala M, et al. A mismatch between self-reported physical work load and the HAQ: early identification of rheumatoid arthritis patients at risk for loss of work productivity. Clin Exp Rheumatol 2009;27:422-9

34. van Roijen L, Essink-Bot ML, Koopmanschap MA, Michel BC, Rutten FF. Societal perspective on the burden of migraine in the Netherlands. Pharmacoeconomics 1995;7:170-9.

35. Ozminkowski RJ, Goetzel RZ, Long SR. A validity analysis of the Work Productivity Short Inventory (WPSI) instrument measuring employee health and productivity. J Occup Environ Med 2003;45:1183-95.

36. Reilly MC, Zbrozek AS, Dukes EM. The validity and reproducibility of a work productivity and activity impairment instrument. Pharmacoeconomics 1993;4:353-65.

37. Goetzel RZ, Ozminkowski RJ, Long SR. Development and reliability analysis of the Work Productivity Short Inventory (WPSI) instrument measuring employee health and productivity. J Occup Environ Med 2003;45:743-62.

38. Zhang W, Gignac MAM, Beaton DE, Tang K, Anis AH, and the Canadian Arthritis Network Work Productivity Group. Productivity loss due to presenteeism among patients with arthritis: Estimates from 4 instruments. J Rheumatol 2010;37:1805-14.

39. Lerner D, Rogers WH, Chang H. Technical report: scoring the Work Limitations Questionnaire (WLQ) and the WLQ index for estimating work productivity loss. (Unpublished data. Revised April 2003, Available from the authors); 2003.

40. Rubin DB. Inference and missing data. Biometrika 1976;72:359-64.

41. Fielding S, Fayers PM, McDonald A, McPherson G, Campbell MK. Simple imputation methods were inadequate for missing not at random (MNAR) quality of life data. Health Qual Life Outcomes 2008;6:57.

42. Olsen MK, Schafer JL. A two-part random effects model for semicontinuous longitudinal data. J Am Stat Assoc 2001;96:730-45.

43. Endicott J, Nee J. Endicott Work Productivity Scale (EWPS): a new measure to assess treatment effects. Psychopharmacol Bull 1997;33:13-6.

44. Wang PP, Badley EM, Gignac M. Exploring the role of contextual factors in disability models. Disabil Rehabil 2006;28:135-40.

45. Wang TJ, Chern HL, Chiou YE. A theoretical model for preventing osteoarthritis-related disability. Rehabil Nurs 2005;30:62-7.

46. Gignac MA, Sutton D, Badley EM. Arthritis symptoms, the work environment, and the future: measuring perceived job strain among employed persons with arthritis. Arthritis Rheum 2007;57:738-47.

47. Allaire SH, Anderson JJ, Meenan RF. Reducing work disability associated with rheumatoid arthritis: identification of additional risk factors and persons likely to benefit from intervention. Arthritis Care Res 1996;9:349-57.

48. Lacaille D, Sheps S, Spinelli JJ, Chalmers A, Esdaile JM.
Identification of modifiable work-related factors that influence the risk of work disability in rheumatoid arthritis. Arthritis Rheum 2004;51:843-52.

49. Burton W, Morrison A, Maclean R, Ruderman E. Systematic review of studies of productivity loss due to rheumatoid arthritis. Occup Med (Lond) 2006;56:18-27.

50. Reavley N, Livingston J, Buchbinder R, Bennell K, Stecki C, Osborne RH. A systematic grounded approach to the development of complex interventions: the Australian WorkHealth Program arthritis as a case study. Soc Sci Med 2009;70:342-50.

51. Gignac MA. Arthritis and employment: an examination of behavioral coping efforts to manage workplace activity limitations. Arthritis Rheum 2005;53:328-36.

52. Chorus AM, Miedema HS, Wevers CW, van der Linden S. Work factors and behavioural coping in relation to withdrawal from the labour force in patients with rheumatoid arthritis. Ann Rheum Dis 2001;60:1025-32

53. Lacaille D, White MA, Backman CL, Gignac MA. Problems faced at work due to inflammatory arthritis: new insights gained from understanding patients' perspective. Arthritis Rheum 2007; 57:1269-79.

54. Uhlig T. Which patients with rheumatoid arthritis are still working? Arthritis Res Ther 2010;12:114.

55. Dadoniene J, Stropuviene S, Venalis A, Boonen A. High work disability rate among rheumatoid arthritis patients in Lithuania. Arthritis Rheum 2004;51:433-9.

56. Chung CP, Sokka T, Arbogast PG, Pincus T. Work disability in early rheumatoid arthritis: higher rates but better clinical status in Finland compared with the US. Ann Rheum Dis 2006;65:1653-7.

57. Borg J, Larsson S, Ostergren PO, Eide AH. The Friction Model a dynamic model of functioning, disability and contextual factors and its conceptual and practical applicability. Disabil Rehabil 2010;32:1790-7.

58. Reisine S, McQuillan J, Fifield J. Predictors of work disability in rheumatoid arthritis patients. A five-year followup. Arthritis Rheum 1995;38:1630-7.

59. Yelin E, Meenan R, Nevitt M, Epstein W. Work disability in rheumatoid arthritis: effects of disease, social, and work factors. Ann Intern Med 1980;93:551-6.

60. Eberhardt K, Larsson BM, Nived K. Early rheumatoid arthritis some social, economical, and psychological aspects. Scand J Rheumatol 1993;22:119-23.

61. Reisine ST, Grady KE, Goodenow C, Fifield J. Work disability among women with rheumatoid arthritis. The relative importance of disease, social, work, and family factors. Arthritis Rheum 1989;32:538-43.

62. Yelin E, Henke C, Epstein W. The work dynamics of the person with rheumatoid arthritis. Arthritis Rheum 1987;30:507-12.

63. Sokka T, Kautiainen H, Mottonen T, Hannonen P. Work disability in rheumatoid arthritis 10 years after the diagnosis. J Rheumatol 1999;26:1681-5.

64. Wolfe F, Hawley DJ. The longterm outcomes of rheumatoid arthritis: Work disability: a prospective 18 year study of 823 patients. J Rheumatol 1998;25:2108-17.

65. Jantti J, Aho K, Kaarela K, Kautiainen H. Work disability in an inception cohort of patients with seropositive rheumatoid arthritis: a 20 year study. Rheumatology 1999;38:1138-41.

66. Eberhardt K, Larsson BM, Nived K, Lindqvist E. Work disability in rheumatoid arthritis - development over 15 years and evaluation of predictive factors over time. J Rheumatol 2007;34:481-7.

67. Young A, Dixey J, Kulinskaya E, Cox N, Davies P, Devlin J, et al. Which patients stop working because of rheumatoid arthritis? Results of five years' follow up in 732 patients from the Early RA Study (ERAS). Ann Rheum Dis 2002;61:335-40.

68. Mau W, Bornmann M, Weber H, Weidemann HF, Hecker H, Raspe

Personal non-commercial use only. The Journal of Rheumatology Copyright @ 2011. All rights reserved 
HH. Prediction of permanent work disability in a follow-up study of early rheumatoid arthritis: results of a tree structured analysis using RECPAM. Br J Rheumatol 1996;35:652-9.

69. Verstappen SM, Watson KD, Lunt M, McGrother K, Symmons DP, Hyrich KL. Working status in patients with rheumatoid arthritis, ankylosing spondylitis and psoriatic arthritis: results from the British Society for Rheumatology Biologics Register. Rheumatology 2010;49:1570-7.

70. Verstappen SM, Boonen A, Bijlsma JW, Buskens E, Verkleij H, Schenk Y, et al. Working status among Dutch patients with rheumatoid arthritis: work disability and working conditions. Rheumatology 2005;44:202-6.

71. Allaire S, Wolfe F, Niu J, LaValley MP, Zhang B, Reisine S. Current risk factors for work disability associated with rheumatoid arthritis: recent data from a US national cohort. Arthritis Rheum 2009;61:321-8.

72. Gignac MA, Cao X, Lacaille D, Anis AH, Badley EM. Arthritis-related work transitions: A prospective analysis of reported productivity losses, work changes, and leaving the labor force. Arthritis Rheum 2008;59:1805-13.

73. Sokka T, Pincus T. Markers for work disability in rheumatoid arthritis. J Rheumatol 2001;28:1718-22.

74. Badley EM, Wang PP. The contribution of arthritis and arthritis disability to nonparticipation in the labor force: a Canadian example. J Rheumatol 2001;28:1077-82.

75. Odegard S, Finset A, Kvien TK, Mowinckel P, Uhlig T. Work disability in rheumatoid arthritis is predicted by physical and psychological health status: a 7-year study from the Oslo RA register. Scand J Rheumatol 2005;34:441-7.

76. Kaptein SA, Gignac MA, Badley EM. Differences in the workforce experiences of women and men with arthritis disability: a population health perspective. Arthritis Rheum 2009;61:605-13.

77. Puolakka K, Kautiainen H, Mottonen T, Hannonen P, Hakala M, Korpela M, et al. Predictors of productivity loss in early rheumatoid arthritis: a 5 year follow up study. Ann Rheum Dis 2005;64:130-3.
78. Shanahan EM, Smith M, Roberts-Thomson L, Esterman A, Ahern $\mathrm{M}$. Influence of rheumatoid arthritis on work participation in Australia. Intern Med J 2008;38:166-73.

79. Doeglas D, Suurmeijer T, Krol B, Sanderman R, van Leeuwen M, van Rijswijk M. Work disability in early rheumatoid arthritis. Ann Rheum Dis 1995;54:455-60.

80. De Roos AJ, Callahan LF. Differences by sex in correlates of work status in rheumatoid arthritis patients. Arthritis Care Res 1999;12:381-91.

81. Machado GP, Gignac MA, Badley EM. Participation restrictions among older adults with osteoarthritis: a mediated model of physical symptoms, activity limitations, and depression. Arthritis Rheum 2008;59:129-35.

82. Mitchell JM, Burkhauser RV, Pincus T. The importance of age, education, and comorbidity in the substantial earnings losses of individuals with symmetric polyarthritis. Arthritis Rheum 1988;31:348-57.

83. Kaarela K, Lehtinen K, Luukkainen R. Work capacity of patients with inflammatory joint diseases. An eight-year follow-up study. Scand J Rheumatol 1987;16:403-6.

84. Reisine S, Fifield J, Walsh SJ, Feinn R. Factors associated with continued employment among patients with rheumatoid arthritis: a survival model. J Rheumatol 2001;28:2400-8.

85. Callahan LF, Bloch DA, Pincus T. Identification of work disability in rheumatoid arthritis: physical, radiographic and laboratory variables do not add explanatory power to demographic and functional variables. J Clin Epidemiol 1992;45:127-38.

86. Newman S. Coping with rheumatoid arthritis. Ann Rheum Dis 1993;52:553-4.

87. Gignac MA, Cao X. "Should I tell my employer and coworkers I have arthritis?" A longitudinal examination of self-disclosure in the work place. Arthritis Rheum 2009;61:1753-61. 